\title{
rhPDGF MEDIATED ROOT COVERAGE PROCEDURE USING CORONALLY ADVANCED FLAP IN TREATMENT OF MULTIPLE RECESSION DEFECTS: A CASE REPORT
}

Preetinder Singh ${ }^{1}$, Yash Paul Dev ${ }^{2}$, Nitin Khuller ${ }^{3}$, Anahita Singh ${ }^{4}$, Prabhjot Kaur ${ }^{5}$, Yashbir Singh Raghav

${ }^{1,3}$ Reader, Department of Periodontology, Swami Devi Dyal Hospital and Dental College, Haryana, India.

${ }^{2}$ Principal and Head, Department of Periodontology, Swami Devi Dyal Hospital and Dental College, Haryana, India.

${ }^{4,5,6}$ Post Graduate Student, Department of Periodontology, Swami Devi Dyal Hospital and Dental College, Haryana, India

\begin{abstract}
\begin{tabular}{c|ccc}
\hline & ABSTRACT
\end{tabular}
Gingival recession has been defined as the term used to characterize the apical shift of the marginal gingiva from its normal position on the crown of the tooth to levels on the root surface beyond the cemento-enamel junction (CEJ). Numerous techniques have been developed for treatment of these defects including rotational and advanced gingival flaps, soft-tissue grafting procedures with autogenous and allograft materials. This paper illustrates a case report of 42 -years-old male patient with a chief complaint of thermal root sensitivity in relation with front teeth of lower jaw and describes a technique to coronally advance the flap in combination with recombinant human platelet-derived growth factor-BB (rhPDGF-BB) (GEM 21S $\mathrm{S}^{\circledR}$ ) to treat multiple gingival recession defects. Patient was followed postoperatively, and healing was evaluated at 1,3 and 6 months, with recession depth as the primary outcome measure. This case report revealed a favourable tissue response to GEM $21 \mathrm{~S}^{\circledR}$ from both clinical and aesthetic points of view showing excellent plastic surgery results for gingiva.
\end{abstract}

Keywords: Coronally advanced flap; GEM 21S $\mathrm{S}^{\circledR}$; Gingival recession; Platelet Derived Growth Factor; rhPDGF-BB;

\section{INTRODUCTION}

Marginal tissue recession, i.e. displacement of the soft tissue margin apical to the cemento-enamel junction (CEJ) with exposure of the root surface, is a common feature in populations with high standards of oral hygiene as well as in populations with poor oral hygiene. ${ }^{1}$ In populations maintaining high standards of oral hygiene, loss of attachment and marginal tissue recession are predominantly found at buccal surfaces ${ }^{1}$ and are frequently associated with the presence of "a wedge shaped defect in the crevicular area of one or several teeth."

Different etiological factors may be responsible for contributing to the condition such as traumatic toothbrushing technique, periodontal disease, thin gingival tissue, pre-eminence of the buccal root, tooth mal-positioning, bone fenestration, frenum pull near the gingival margin $^{1}$ and iatrogenic factors. ${ }^{3}$
Facial gingival recessions in the anterior region represent one of the most important challenges for periodontists. The domain of periodontics has been changed from being strictly a healthy service to one where smile enhancement has been brought to the forefront of treatment planning. Surgical correction of exposed root surface has become a remarkably successful and predictable procedure. ${ }^{4}$

A variety of surgical procedures have been described to achieve soft tissue coverage of exposed root surfaces such as: connective tissue graft $(\mathrm{CTG}){ }^{5}$ free gingival graft $(\mathrm{FGG})^{5}$, FGG followed by coronally repositioned flap, lateral pedicle graft, guided tissue regeneration (GTR), ${ }^{5}$ double papillae graft, semilunar coronally repositioned flap, acellular dermal allograft, ${ }^{5}$ coronally repositioned flap with enamel matrix derivative (EMD), ${ }^{5}$ and coronally repositioned flaps 
with recombinant human platelet-derived growth factor-BB with $\beta$-tricalcium phosphate (rhPDGF$\mathrm{BB} / \beta-\mathrm{TCP}){ }^{6-8}$

Platelet-derived growth factor (PDGF) is one of the most thoroughly studied growth factor in periodontics. Since the late 1980s, PDGF has been known to promote regeneration of cementum, periodontal ligament, and bone, and several studies have been published on the stimulatory effects of PDGF on chemotaxis and proliferation of PDL and alveolar bone cells in both animals and humans. ${ }^{9,10}$

Purified recombinant human PDGF (rhPDGF), in combination with synthetic matrices such as beta tricalcium phosphate ( $\beta$-TCP) or allografts, has been studied extensively and given promising results. ${ }^{6,11-14}$ Studies have shown that PDGF-BB acts as a magnet to promote rapid cell migration (chemotaxis) into the injured region with subsequent proliferation (mitogenesis) of osteoblasts and periodontal ligament fibroblasts by binding to well-characterized cell surface receptors. ${ }^{9,15-19}$ PDGF has also been shown to be important during embryonic development. ${ }^{20}$

A new wound healing and bone regeneration technology termed growth-factor enhanced matrix $\left(\right.$ GEM $\left.21 \mathrm{~S}^{\circledR}\right)$ has recently become available for clinical use. (It is a product of BioMimetic Therapeutics, TN, USA). This graft material consists of a concentrated solution of pure recombinant human platelet-derived growth factor (rhPDGF-BB), the synthetic form of the body's key natural wound healing stimulator PDGF$\mathrm{BB}$, and an osteoconductive (bone scaffold) matrix. This is the first available purified, recombinant (synthetic) growth factor product and is the result of over a decade of extensive research. Clinical and animal study results, using this graft material in challenging periodontal and peri-implant defects demonstrate that it is capable of simultaneously promoting wound healing, regeneration of bone, and acceleration of gingival attachment gain.

This case report illustrates a technique to coronally advance the flap in combination with recombinant human platelet-derived growth factor-BB (rhPDGF-BB) (GEM 21 $\mathrm{S}^{\circledR}$ ) to treat multiple recession defects.

\section{CASE REPORT}

A 42-years-old, systemically healthy male patient presented with a chief complaint of thermal root sensitivity present in lower front teeth (i.e. 31, 32, 33). Additionally, he wanted to improve what he perceived to be the unsightly appearance of the teeth. On examination, the patient presented with Miller's Class $\mathrm{I}^{21+}$ gingival recession of $3 \mathrm{~mm}$ in $33,3 \mathrm{~mm}$ in 32 and 1 $\mathrm{mm}$ in 31 . The patient served as his own control, so that extraneous factors such as oral hygiene and compliance were controlled within each subject.

Following screening examination, the patient received instructions related to proper oral hygiene measures. At the treatment site, a brushing technique was prescribed that minimized apically directed forces to the soft tissue. Surgical treatment of the recession defect was not scheduled until the patient could demonstrate adequate supragingival plaque control.

The materials were consisted of: GEM $21 \mathrm{~S}^{\circledR}$ and 24\% EDTA as root biomodifier. Together these materials are known to promote wound healing by improving and promoting cellular ingrowth into the recession defect. In addition, they physically prevent the collapse of the soft tissues onto the root surface and facilitate the stabilization of blood clot by providing a osteoconductive scaffold for new tissue regeneration.

Following clinical parameters were assessed:

1. Gingival recession depth $(\mathrm{GR})^{22}$

2. Clinical attachment level $(\mathrm{CAL})^{22}$

3. Clinical probing depth $(\mathrm{PD})^{22}$

4. Width of keratinized tissue (WKT) $)^{22}$

\section{Surgical Procedure (Figure 1-6)}

After evaluation of pre-clinical records and obtaining adequate local anaesthesia, two horizontal bevelled incisions were given, mesial and distal to the recession defect located at a distance from the tip of the anatomical papillae equal to the depth of the recession plus $1 \mathrm{~mm}$. This was followed by two bevelled oblique, slightly divergent, incisions starting at the end of the two horizontal incisions and extending to the alveolar mucosa.

The resulting trapezoidal-shaped flap was elevated with a split-full-split approach in the coronalapical direction. The releasing vertical incisions were 


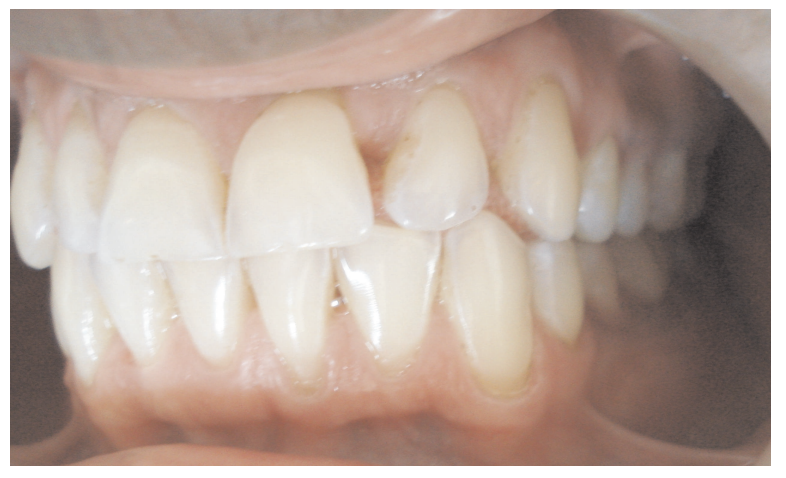

Figure 1: Pre-operative View

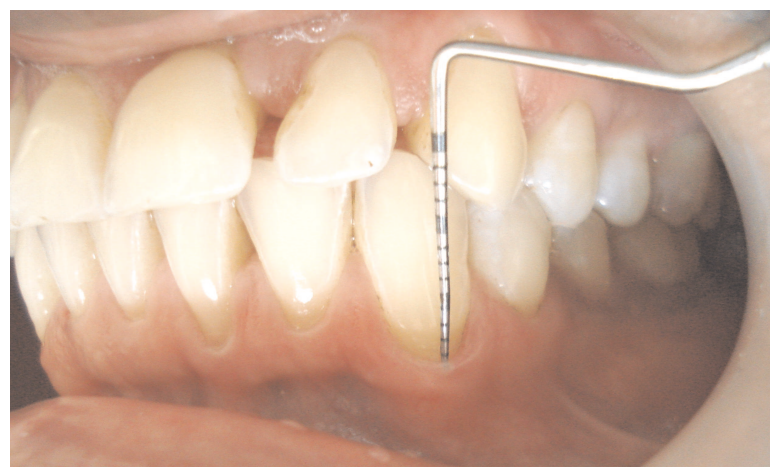

Figure 2: Baseline

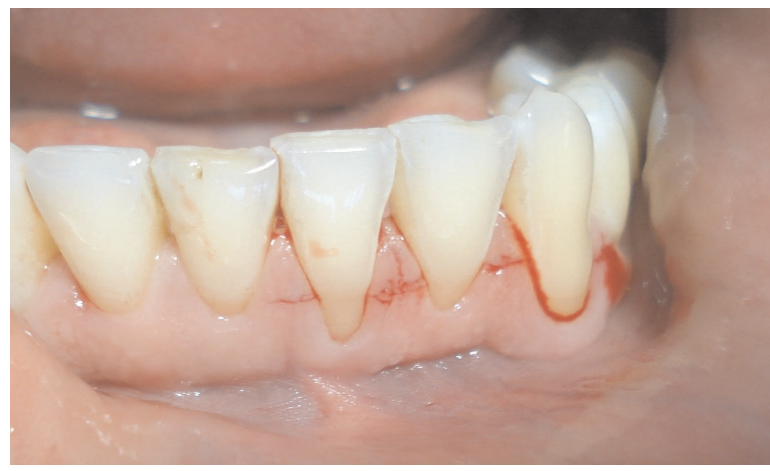

Figure 3: Horzontal incision

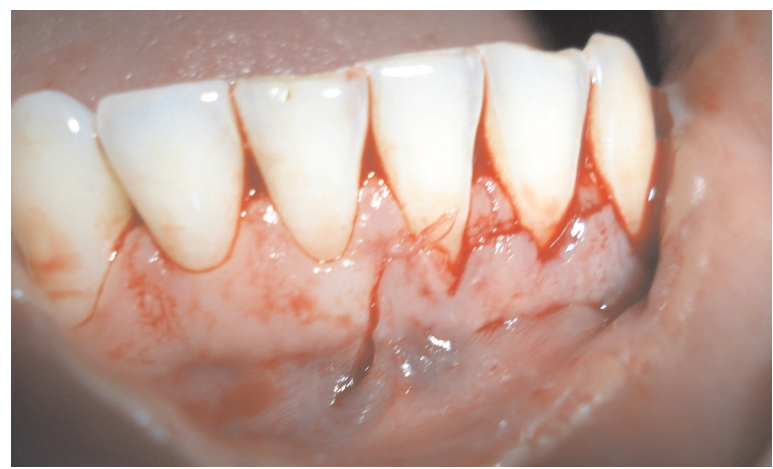

Figure 4: Vertical incision

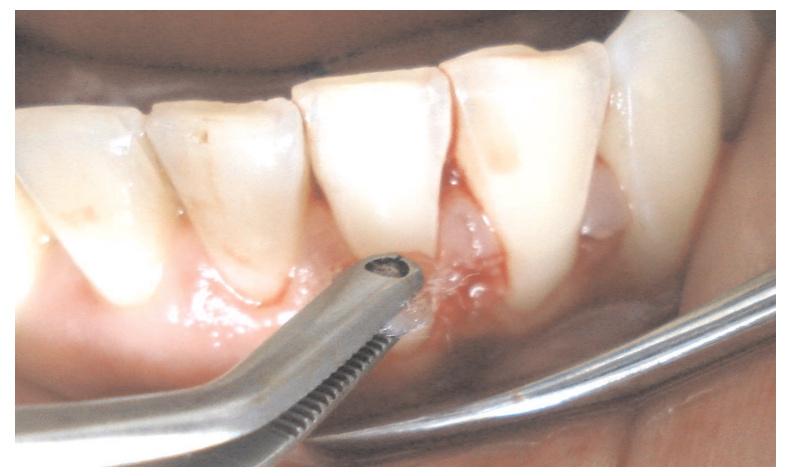

Figure 5: Root Biomodification

elevated split thickness keeping the blade parallel to the bone plane, thus leaving the periosteum to protect the underlying bone in the lateral areas of the flap. Apical to bone exposure flap elevation continued split thickness and finished when it was possible to move the flap passively in the coronal direction. In order to permit the coronal advancement of the flap, all muscle insertions present in the thickness of the flap were eliminated. Coronal mobilization of the flap was considered "adequate" when the marginal portion of the flap was able to passively reach a level coronal to the CEJ of the tooth with the recession defect.

The facial soft tissue of the anatomic interdental papillae coronal to the horizontal incisions was deepithelized to create connective tissue beds to which the surgical papillae of the coronally advanced flap were sutured. ${ }^{23}$ The exposed root surface, after thorough root planing, was conditioned with ethylenediamine- tetraacetic acid (EDTA- $24 \%$ ) for 2 minutes to remove the smear layer and thoroughly rinsed with sterile saline. Any remaining PDL tissue coronal to the alveolar bone was preserved. The rhPDGF-BB solution was then applied to the exposed root surface and to the coronal ligament fibers. A small amount of $\beta$-TCP was saturated with the rh- PDGF-BB solution and placed below the CEJ, over the denuded root surface and extending approximately 2 to $3 \mathrm{~mm}$ onto the adjacent bone.

The tissue flap was then secured at the level of the CEJ by suturing the flap to the de-epithelialized papillae regions with 3-0 non-resorbable sutures. The vertical incisions were closed with 3-0 non-resorbable sutures. Any remaining rhPDGFBB solution was dispensed onto the coronally advanced flap, followed by placement of tin foil and periodontal dressing. 
Requisite post-operative instructions and medications were advised to the patient. The patient was given amoxicillin and cloxacillin combination for antibiotic coverage and a combination of diclofenac sodium and paracetamol as an anti-inflammatory drug. Chlorohexidine mouthwash was also prescribed, to be used twice daily for two weeks.

\section{Post Surgical Follow up}

Patient was called after 24 hours for check up to evaluate discomfort, swelling, pain, any bleeding or displacement of periodontal pack. One week following surgery, periodontal pack and sutures were removed and area irrigated with saline. Patient was recalled every 2 weeks following surgery for 1 month and subsequently every month for the next 6 months for examination of the treated surgical site. Clinical measurements recorded pre-operatively, were repeated at $1^{\text {st }}$ month, $3^{\text {rd }}$ month and $6^{\text {th }}$ month post-operatively.

\section{RESULTS (Figure 7-8)}

At 6 months, there was no residual recession w.r.t 33. Various parameters recorded at baseline and post-operatively are shown in the tables 1 and 2, indicating $100 \%$ reduction in gingival recession depth and appreciable values of CAL, PD and WKT, when compared from baseline to 6 months w.r.t 33. Complete reduction in gingival recession, however, was not achieved w.r.t. 31, 32, although, there was a significant decrease in the gingival recession depth along with significant result in other parameters. The tissue appeared healthy, with no visible signs of inflammation.

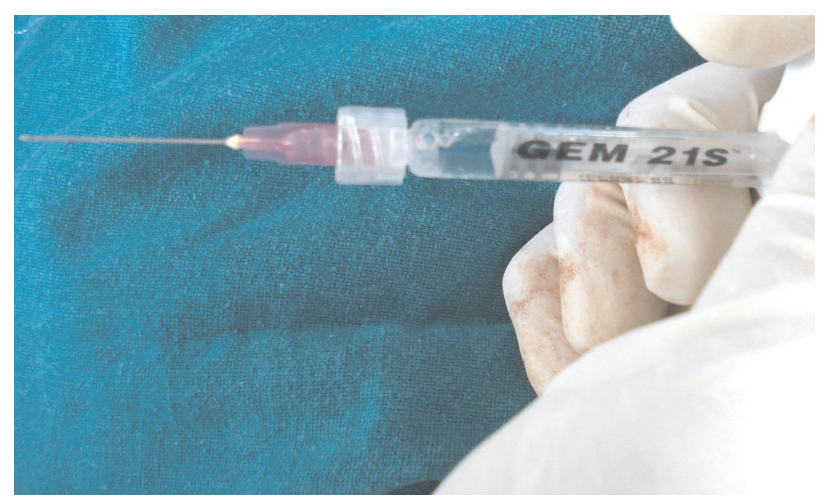

Figure 6: GEM 21S®

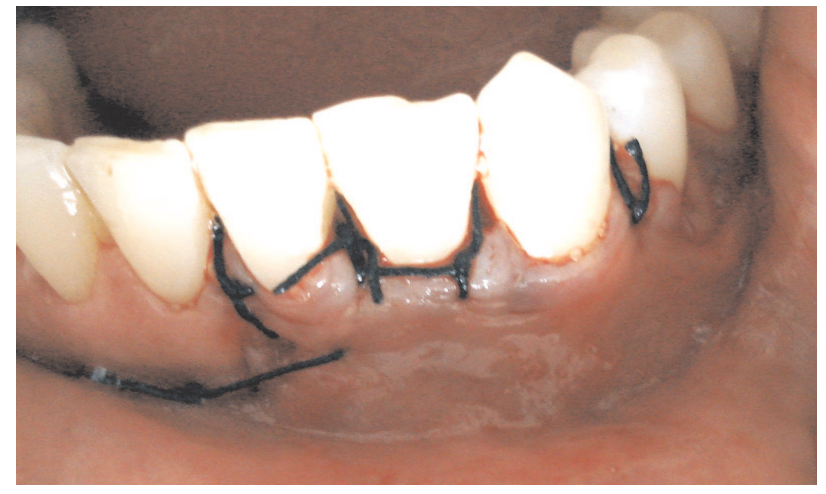

Figure 7: Coronal advancement of flap and sutures

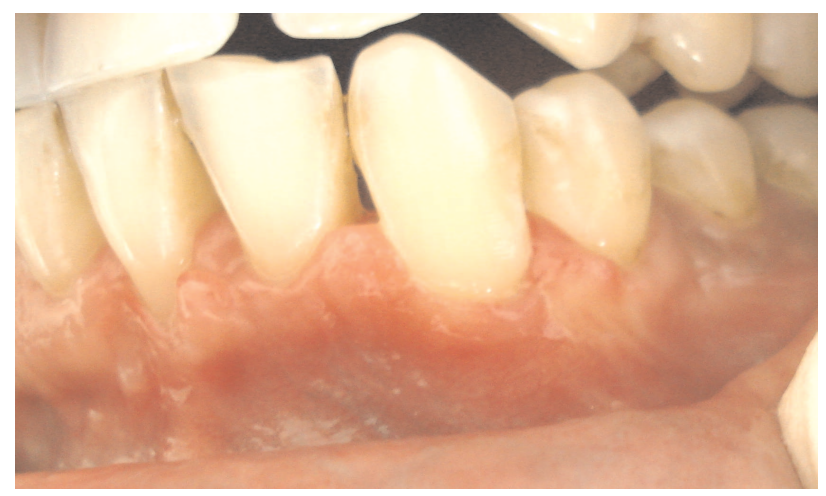

Figure 8: Post operative at 6 months (Full root coverage w.r.t. 33)

Table 1: Periodontal parameters

(GR - gingival recession, CAL - clinical attachment level)

\begin{tabular}{|c|c|c|c|c|c|c|}
\hline & \multicolumn{3}{|c|}{ GR } & \multicolumn{3}{|c|}{ CAL } \\
\hline Site & Baseline & $\begin{array}{c}3^{\text {rd }} \\
\text { Month }\end{array}$ & $\begin{array}{c}6^{\text {th }} \\
\text { Month }\end{array}$ & Baseline & $\begin{array}{c}3^{\text {rd }} \\
\text { Month }\end{array}$ & $\begin{array}{c}6^{\text {th }} \\
\text { Month }^{\text {M }}\end{array}$ \\
\hline 33 & $3 \mathrm{~mm}$ & $2 \mathrm{~mm}$ & 0 & $4 \mathrm{~mm}$ & $3 \mathrm{~mm}$ & 0 \\
\hline 32 & $2 \mathrm{~mm}$ & $1 \mathrm{~mm}$ & $1 \mathrm{~mm}$ & $3 \mathrm{~mm}$ & $1 \mathrm{~mm}$ & $1 \mathrm{~mm}$ \\
\hline 31 & $2 \mathrm{~mm}$ & $1 \mathrm{~mm}$ & $1 \mathrm{~mm}$ & $3 \mathrm{~mm}$ & $1 \mathrm{~mm}$ & $1 \mathrm{~mm}$ \\
\hline
\end{tabular}

Table 2: Periodontal parameters

(WKT - width of keratinized tissue, PD - probing depth

\begin{tabular}{|c|c|c|c|c|c|c|}
\hline & \multicolumn{3}{|c|}{ WKT } & \multicolumn{3}{|c|}{ PD } \\
\hline Site & Baseline & $\begin{array}{c}3^{\text {rd }} \\
\text { Month }\end{array}$ & $\begin{array}{c}6^{\text {th }} \\
\text { Month }\end{array}$ & Baseline & $\begin{array}{c}3^{\text {rd }} \\
\text { Month }\end{array}$ & $\begin{array}{c}6^{\text {th }} \\
\text { Month }\end{array}$ \\
\hline 33 & $3 \mathrm{~mm}$ & $4 \mathrm{~mm}$ & $4 \mathrm{~mm}$ & $2 \mathrm{~mm}$ & $1 \mathrm{~mm}$ & $1 \mathrm{~mm}$ \\
\hline 32 & $4 \mathrm{~mm}$ & $5 \mathrm{~mm}$ & $6 \mathrm{~mm}$ & $1 \mathrm{~mm}$ & $1 \mathrm{~mm}$ & $1 \mathrm{~mm}$ \\
\hline 31 & $2 \mathrm{~mm}$ & $2 \mathrm{~mm}$ & $3 \mathrm{~mm}$ & $1 \mathrm{~mm}$ & $1 \mathrm{~mm}$ & $1 \mathrm{~mm}$ \\
\hline
\end{tabular}

\section{DISCUSSION}

This case report proves that it is possible to treat multiple periodontal recession defects with GEM $21 \mathrm{~S}{ }^{\circledR}$ with a coronally advanced flap with optimum results in terms of various clinical parameters (as 
shown in tables 1 and 2) and from aesthetics point of view.

Several studies have supported the concept of using rhPDGF- BB and bone grafts in periodontal defects. In a pilot study, McGuire and Scheyer ${ }^{6}$ demonstrated similar ability to cover Miller's ${ }^{21}$ Class I and II recession defects with either subepithelial CTGs or coronally positioned flaps over rhPDGF-BB $/ \beta$ TCP-treated sites. McGuire et al. ${ }^{7,8}$ evaluated human histology and microcomputed tomography (micro CT) after either a CTG or coronally repositioned flap with rhPDGF-BB/ $\beta$-TCP and showed that although both techniques provided equal clinical root coverage, only the coronally repositioned flaps with $\mathrm{rhPDGF}-\mathrm{BB} / \beta-$ TCP showed histologic and micro CT evidence of new cementum, PDL, and bone formation. This was confirmed by other studies as well, such as done by Myrons Nevins et $\mathrm{al}^{13}$, Myron Nevins ${ }^{12}$ and Camelo M et al. ${ }^{11}$

This targeted therapeutic approach promises to increase the predictability of regenerative outcomes suggesting the potential of rhPDGF-BB $+\beta-\mathrm{TCP}$ as a viable alternative to the $\mathrm{CTG}$ and other therapies in the treatment of gingival recession defects.

The positive result of this study supports the need for a proper clinical study to determine the viability of this approach to treat root coverage.

\section{CONCLUSION}

Within the limits of this case, the use of GEM $21 \mathrm{~S}^{\circledR}$ may represent an acceptable alternative to various other procedures for covering gingival recession defects. The present study was a short term clinical study with no histological evaluation. Studies should be designed with large sample sizes and histological evaluation to further compare the predictability of above said procedure, as there is paucity of literature regarding the same.

\section{REFERENCES}

1. Loe H, Anerud A, Boysen H. The natural history of periodontal disease in man: Prevalence, severity and extent of gingival recession. J Periodontol 1992; 63: 489-495.

2. Sangnes G, Gjermo P. Prevalence of oral soft and hard tissue lesions related to mechanical tooth cleaning procedures. Community Dent Oral Epidemiol 1976; 4: 77-83.
3. Lindhe J, Socransky SS, Nyman S, Westfelt E. Dimensional alteration of the periodontal tissues following therapy. Int $\mathrm{J}$ Periodontic Restorative Dent 1987; 7(2): 9-22.

4. Wennstrom JL. Mucogingival therapy. Ann Periodontol 1996; 1: 671-701.

5. Chambrone L, Sukekava F, Araújo MG, Pustiglioni FE, Chambrone LA, Lima LA. Root-coverage procedures for the treatment of localized recession-type defects: A Cochrane systematic review. J Periodontol 2010;81:452-478.

6. McGuire MK, Scheyer ET. Comparison of recombinant human plateletderived growth factor-BB plus beta tricalcium phosphate and a collagen membrane to subepithelial connective tissue grafting for the treatment of recession defects: A case series. Int J Periodontics Restorative Dent 2006;26:127-133.

7. McGuire MK, Scheyer T, NevinsM, Schupbach P. Evaluation of human recession defects treated with coronally advanced flaps and either purified recombinant human platelet-derived growth factor-BB with beta tricalcium phosphate or connective tissue: A histologic and microcomputed tomographic examination. Int J Periodontics Restorative Dent 2009; 29:7-21.

8. McGuire MK, Scheyer ET, Schupbach P. Growth factormediated treatment of recession defects: A randomized controlled trial and histologic and microcomputed tomography examination. J Periodontol 2009; 80: 550-564.

9. Lynch SE, Williams RC, Polson AM, et al. A combination of platelet-derived and insulin-like growth factors enhances periodontal regeneration. J Clin Periodontol 1989;16:545-558.

10. Matsuda N, Lin WL, Kumar MI, Cho MI, Genco RJ, Mitogenic, chemotactic, and synthetic responses of rat periodontal ligament fibroblastic cells to polypeptide growth factors in vitro. J Periodontol 1992;63:515-525.

11. Camelo M, Nevins ML, Schenk RK, Lynch SE, Nevins M. Periodontal regeneration in human Class II furcations using purified recombinant human platelet-derived growth factorBB (rhPDGF-BB) with bone allograft. Int J Periodontics Restorative Dent 2003;23(3):213-25.

12. Nevins M, Camelo M, Nevins ML, Schenk RK, Lynch SE. Periodontal regeneration in humans using recombinant human platelet-derived growth factor-BB (rhPDGF-BB) and allogenic bone. J Periodontol 2003;74(9):1282-92.

13. Nevins M, Giannobile WV, McGuire MK, Kao RT, Mellonig JT, Hinrichs JE et al. Platelet-derived growth factor stimulates bone fill and rate of attachment level gain: results of a large multicenter randomized controlled trial. J Periodontol 2005;76(12):2205-15.

14. McGuire MK, Kao RT, Nevins M, Lynch SE. rhPDGF-BB promotes healing of periodontal defects: 24 -month clinical and radiographic observations. Int J Periodontics Restorative Dent 2006;26(3):223-31. 
15. Lynch SE, Genco RJ, Marx RE, editors. Tissue engineering: Applications in maxillofacial surgery and periodontics. Chicago, Ill: Quintessence Publishing Co; 1999.

16. Centrella M, McCarthy TL, Kusmik WF, Canalis E. Relative binding and biochemical effects of heterodimeric and homodimeric isoforms of platelet-derived growth factor in osteoblast-enriched cultures from fetal rat bone. J Cell Physiol 1991;147(3):420-6.

17. Piché JE, Graves DT. Study of the growth factor requirements of human bone-derived cells: a comparison with human fibroblasts. Bone. 1989;10(2):131-8.

18. Bowen-Pope DF, Van Koppen A, Schatteman G. Is PDGF really important? Testing the hypotheses. Trends Genet. 1991 Nov-Dec;7(11-12):413-8.

19. Soriano P. Abnormal kidney development and hematological disorders in PDGF beta-receptor mutant mice. Genes Dev 1994;8(16):1888-96.
20. Schatteman GC, Morrison-Graham K, van Koppen A, Weston JA, Bowen-Pope DF. Regulation and role of PDGF receptor alphasubunit expression during embryogenesis. Development 1992;115(1): 123-31.

21. Miller PD Jr. A classification of marginal tissue recession. Int J Periodontics Restorative Dent 1985;5(2):8-13.

22. Wang HL, Bunyaratavej P, Labadie M, Shyr Y, MacNeil RL. Comparison of 2 clinical techniques for treatment of gingival recession. J Periodontol 2001;72(10):1301-11.

23. deSanctis M, Zucchelli G. Coronally advanced flap: a modified surgical approach for isolated recession-type defects: three-year results. J Clin Periodontol 2007;34(3):262-8. 